\title{
Compositional Analysis of Electrospun Zn-Doped Ferrite Nanofibers using an Electron Probe Microanalyzer
}

\author{
Candyce N. Collins, Gibin George, Zhiping Luo* \\ Department of Chemistry and Physics, Fayetteville State University, Fayetteville, USA \\ * Corresponding author: zluo@uncfsu.edu
}

Ortho ferrites with the general formula $\mathrm{AFeO}_{3}(\mathrm{~A}=\mathrm{Bi}, \mathrm{La}, \mathrm{Sr}$, etc. $)$ are magnetic perovskite structured materials that are extensively studied as promising candidates for solid-oxide fuel cells [1], catalytic converters [2], oxygen evolution reaction [3], photocatalysts [4], and gas sensors [5]. Although the perovskite materials can be prepared using various techniques, sol-gel assisted electrospinning process is a viable technique for the fabrication of highly porous and high aspectratio nanostructures in bulk quantities [6]. Nanostructured $\mathrm{NdFeO}_{3}$ perovskite oxide exhibits interesting properties, and these materials are identified as suitable candidates for carbon monoxide [7] and acetone when doped with $\mathrm{Pd}$ [8] with high sensitivity and selectivity. Besides, $\mathrm{NdFeO}_{3}$ is recognized as the promising candidate for the sulfur-oxygen solid oxide fuel cells [9]. The partial replacement of trivalent Fe ions with divalent ions can significantly improve the properties and performance in the several applications owing to the presence of oxygen vacancies. In this work, an attempt is made to dope divalent $\mathrm{Zn}$ in the ferrite fibrous matrix.

A homogeneous precursor solution containing $2.0 \mathrm{~g}$ polyvinylpyrrolidone (PVP) (molecular weight $\sim 1,200,000 \mathrm{~g} / \mathrm{mol}$ ), $0.07 \mathrm{M}$ neodymium (III) nitrate, $0.063 \mathrm{M}$ iron (III) nitrate and 0.007 $\mathrm{M}$ zinc nitrate, in a $20 \mathrm{~mL} 50 / 50$ mixture of $N, N$-dimethylformamide (DMF) and ethanol, was prepared by vigorous mixing for $12 \mathrm{~h}$. The electrospinning was conducted at room temperature with an applied voltage of $18 \mathrm{kV}$, the flow rate of $500 \mu \mathrm{L} / \mathrm{h}$ and the spinneret to collector distance of $17 \mathrm{~cm}$. The obtained electrospun precursor composite fibers were subsequently calcined at $700{ }^{\circ} \mathrm{C}$ in air for $5 \mathrm{~h}$ at a ramp of $1{ }^{\circ} \mathrm{C} / \mathrm{min}$ to obtain the oxide nanofibers. Samples were coated with carbon and analyzed in a JEOL field-emission JXA-8530F Electron Probe Microanalyzer (EPMA), which was equipped with an SDD X-ray energy-dispersive spectrometer (EDS), and five wavelength-dispersive spectrometers (WDSs) worked at $15 \mathrm{kV}$.

Fig. 1(a\&b) shows SEM images of $\mathrm{Zn}$-doped $\mathrm{NdFeO}_{3}$ nanofibers after calcination. The average fiber diameter significantly decreased upon calcination as compared with the as-spun composite fibers, with an average fiber diameter $<120 \mathrm{~nm}$. The EDS analysis, as shown in Fig. 1(c), confirms that the composition of the obtained fibers is stoichiometric to that of $\mathrm{NdFeO}_{3}$ but the presence $\mathrm{Zn}$ is insignificant. Further the composition is evaluated with WDS analysis, which clearly reveals the presence of $\mathrm{Zn}$ in the $\mathrm{NdFeO}_{3}$ perovskite nanofibers [10].

\section{References}

[1] L. dos Santos-Gómez, J.M. Compana, S. Bruque, et al., J. Power Sources 279 (2015), p. 419.

[2] K. Beppu, A. Demizu, S. Hosokawa, et al., ACS Appl. Mater. Interfaces 10 (2018), p. 22182.

[3] E. Omari, M. Omari, D. Barkat, Polyhedron 156 (2018), p. 116.

[4] M. Ghaffari, P.Y. Tan, M.E. Oruc, O.K. Tan, M.S. Tse, M. Shannon, Catal. Today 161 (2011), p. 70.

[5] N.N. Toan, S. Saukko, V. Lantto, Phys. B Condens. Matter 327 (2003), p. 279.

[6] G. George, S.L. Jackson, C.Q. Luo, et al., Ceram. Inter. 44 (2018), p. 21982. 
[7] T.G. Ho, T.D. Ha, Q.N. Pham, H.T. Giang, T.A.T. Do, N.T. Nguyen, Adv. Nat. Sci. Nanosci. Nanotechnol. 2 (2011), p. 015012.

[8] Z. Wu, R. Zhang, M. Zhao, S. Fang, Z. Han, J. Hu, K. Wang, Int. J. Miner. Metall. Mater. 19 (2012), p. 141.

[9] T. Chen, L. Shen, F. Liu, W. Zhu, Q. Zhang, X. Chu, J. Rare Earths 30 (2012), p. 1138.

[10] This work was supported by NSF PREM program DMR 1827731.
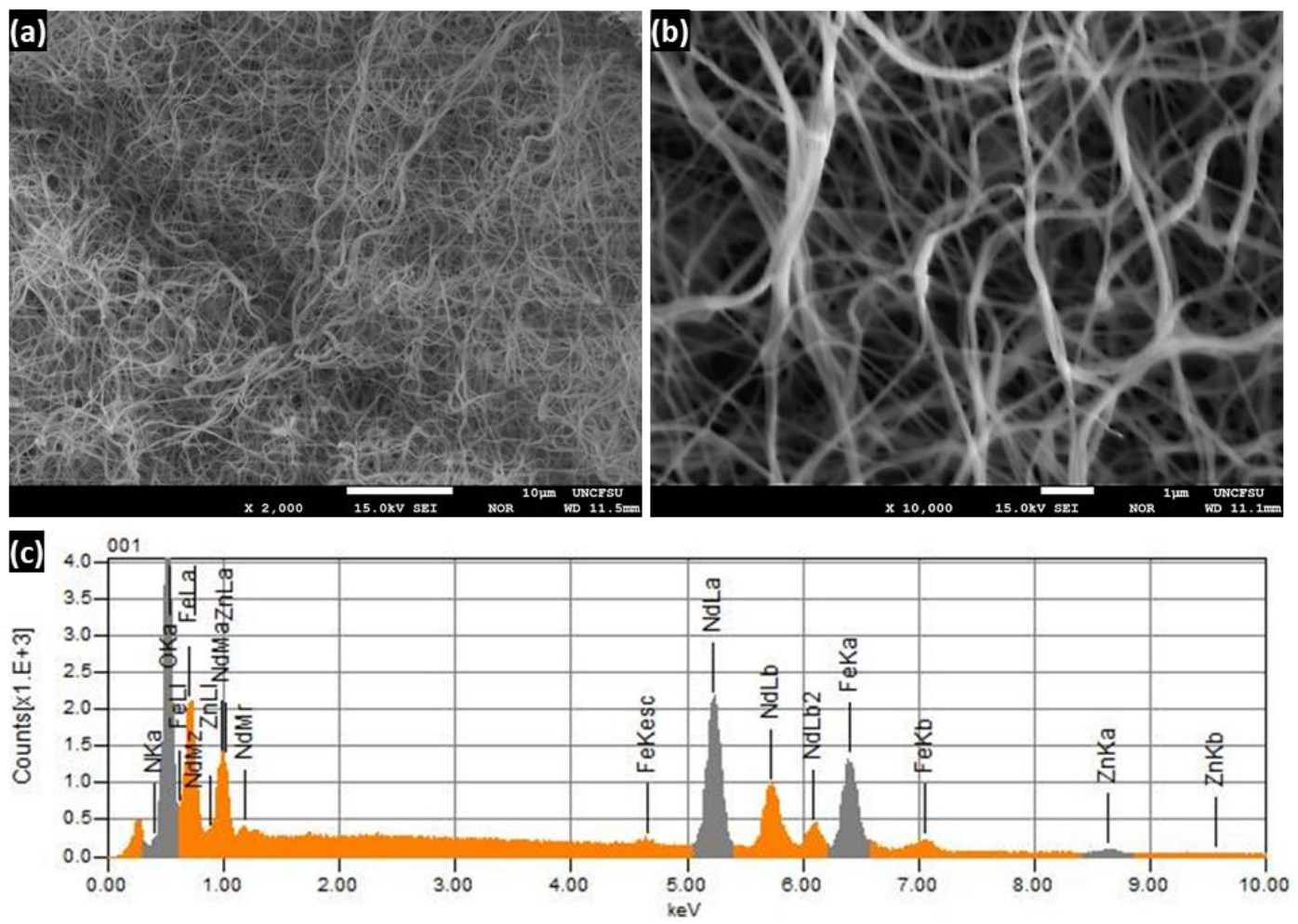

Figure 1. (a) Low and (b) high magnification SEM images of electrospun $\mathrm{Zn}-\mathrm{NdFeO}_{3}$ nanofibers, and (c) the corresponding EDS spectrum.

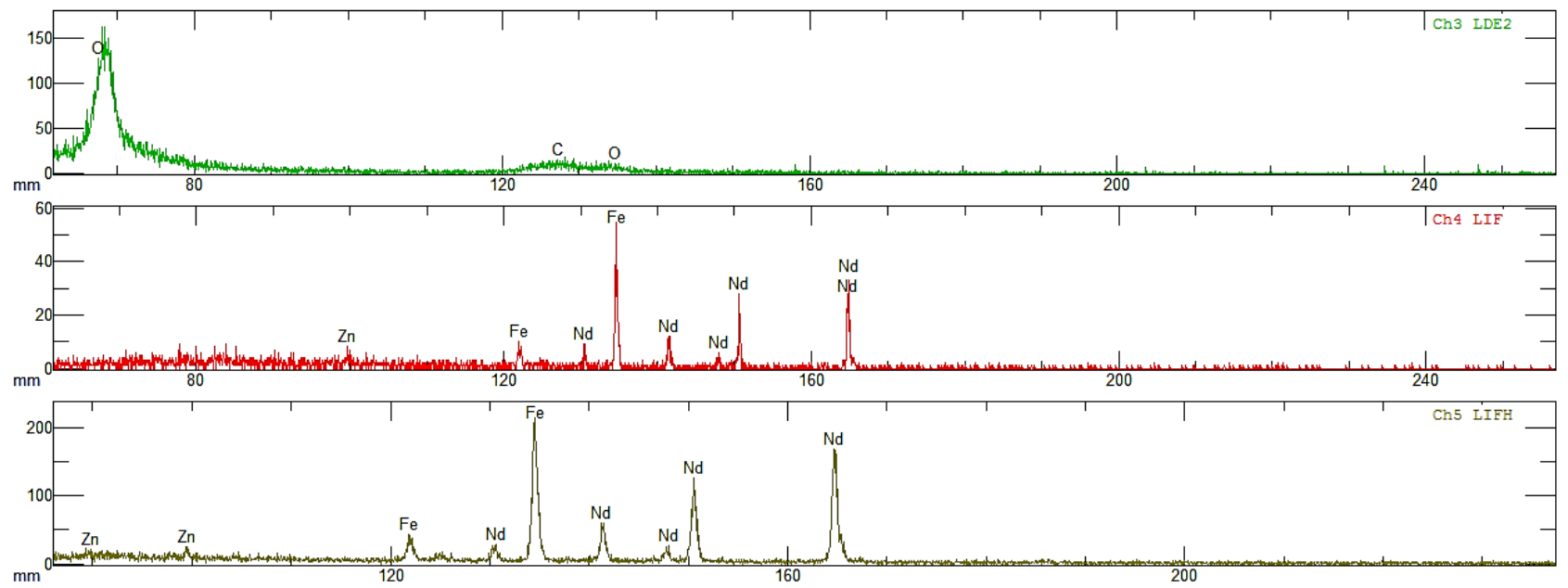

Figure 2. WDS spectra of electrospun $\mathrm{Zn}-\mathrm{NdFO}_{3}$ nanofibers obtained using different crystals. 